\title{
Valorização docente na carreira dos professores dos municípios de General Carneiro - Guamiranga e Mallet - PR
}

\author{
Teaching valuation in the teachers' career in the municipalities of general carneiro - Guamiranga and \\ Mallet - PR
}

\author{
Cassiana Kusznerik†, Joseli Ap. Vieira Guimarães \\ Gonçalves"l
}

Como citar esse artigo. Kusznerik, C.; Guimarães, J.A.V.; Oliveira, V.C.; Gonçalves, V.O.J. Valorização docente na carreira dos professores dos municípios de General Carneiro - Guamiranga e Mallet - PR. Revista Mosaico, v.11, n.2, p. 87 - 94, 2020.

\begin{abstract}
Resumo
O objetivo principal do estudo é compreender se há ou não a valorização da carreira dos docentes nos municípios de General Carneiro, Guamiranga e Mallet - PR, abordando os aspectos de formação, último nível da tabela de vencimento e a variável do tempo que o professor leva para alcançar o último nível do plano de carreira. O trabalho tem como referências Grochoska (2016), Masson e Moretti (2015) e Scheibe (2010). O levantamento de dados sobre os municípios foi realizado através do Caderno do Instituto Paranaense de Desenvolvimento Econômico e Social (IPARDES) de 2020, tabelas salariais e Planos de Carreira dos docentes das redes municipais disponibilizados pelas prefeituras. A metodologia é a descritiva, bibliográfica e documental. As informações coletadas podem ser encontradas em sites oficiais, documentos disponibilizados pelas secretarias municipais de educação e prefeituras. Os resultados revelam a desvalorização da carreira docente nesses municípios. Anecessidade de ampliar a pesquisa é destacada, pois os dados mostram outras fragilidades nos planos de carreira dos docentes das redes municipais pesquisadas.
\end{abstract}

Nota da Editora. Os artigos publicados na Revista Mosaico são de responsabilidade de seus autores. As informações neles contidas, bem como as opiniões emitidas, não representam pontos de vista da Universidade de Vassouras ou de suas Revistas.

Palavras-chave: Valorização Docente, Formação, Vencimento Final, Variável do Tempo.

\begin{abstract}
The main objective of the study is to understand whether there is valuation of the teachers' career or not in the municipalities of General Carneiro, Guamiranga and Mallet - PR, addressing the aspects of training, the last level of salary table and the time variable that the teacher takes to reach the last level of the career path. The work has as references Grochoska (2016), Masson and Moretti (2015) and Scheibe (2010). Data survey about the municipalities was carried out through the do Caderno do Instituto Paranaense de Desenvolvimento Econômico e Social (IPARDES) of 2020, salary tables and teaching Career Plans of the municipal education made available by the municipality administration. The methodology is descriptive, bibliographic and documentary one. Information collected can be found on official websites, documents made available by the municipal secretariats of education and municipality administration. The results reveal devaluation of the teaching career in these municipalities. The need to expand the research is highlighted because the data show other weaknesses in the teachers' career plans of the municipal networks surveyed.

Keywords: Teacher Valuation, Training, Final Salary, Time Variable.
\end{abstract}

\section{Introdução}

O presente trabalho tem como objetivo compreender se há ou não valorização da carreira docente nos municipios de General Carneiro, Guamiranga e Mallet-PR, abordando os aspectos da formação, último nível da tabela de vencimento e variável do tempo que o professor leva para alcançar o último nível do plano de carreira.

Os municípios elencados possuem características gerais análogas que justificam sua escolha no presente trabalho. Para tanto buscamos, em um primeiro momento, caracterizar os municípios e o perfil de suas redes municipais de educação. Na sequência, abordamos o aspecto de formação e as leis que instituem os planos de carreira docente nos três municípios em escopo no estudo, no que tange à formação mínima requerida para a atuação docente, carga horária semanal e remuneração inicial da carreira.

A seguir, tecemos algumas reflexões sobre o aspecto do vencimento contido nas tabelas dos planos de carreira, pontuamos a definição dele de acordo com autores que estudam sobre o tema, considerando-o um elemento importante para a valorização da carreira docente.

Na próxima seção, analisamos pontos importantes das tabelas salariais contidas nos planos de carreira, tendo como base os editais de concursos públicos desses

Afiliação dos autores:

† Formada em Pedagogia pela (UNICENTRO), atuou como bolsista no Programa de Iniciação à Docência (PIBID). Pós-graduada em Educação Infantil pela Faculdade São Braz. Graduanda em Ciências Contábeis pela Universidade Estadual do Centro-Oeste, Paraná, Brasil.

\Licenciada em História (UNICENTRO/PR) e Artes Visuais (UNC/SC). Professora da Educação Básica, Pós-graduada em História do Paraná e Metodologia da Música (FACEL).

Membro do Grupo de Pesquisa Estado, Políticas e Gestão em Educação (UNICENTRO/PR), Mestranda da Pós-Graduação em Educação da UNICENRO, Paraná, Brasil.

\& Graduada em Pedagogia pela (UNICENTRO/PR), Mestranda na mesma instituição, membro do grupo de Estado, Políticas e Gestão em Educação, Paraná, Brasil.

\| Mestranda em Educação pelo PPGE - Unicentro. Membro do Grupo de pesquisa Estado, Políticas e Gestão em Educação. Graduada Licenciatura em Pedagogia, Paraná, Brasil. 
municípios. Percebemos que existe incongruência no que se refere ao aspecto da formação inicial e continuada dos docentes, interferindo de maneira contundente na questão do vencimento final e no aspecto da variável do tempo que se leva para alcançar o último nível da carreira.

$\mathrm{Na}$ sequência, a partir dos documentos consultados, tecemos uma breve análise sobre o conceito de valorização e a carreira dos docentes nos três municípios e ao término do trabalho destacamos a ocorrência do processo de desvalorização. Apontamos esse processo porque ao abordarmos os três aspectos que a compõem percebemos a permanência dos docentes em níveis que rebaixam sua formação, que os planos de carreira não contemplam maiores níveis de formação e que os docentes levam em média de 25 anos para alcançar o último nível do vencimento do plano nesses municípios, quando chegam.

\section{Caracterização e perfil da rede municipal de educação dos municípios de General Carneiro, Guamiranga e Mallet}

Para compreender se há ou não valorização da carreira docente nos municípios de General Carneiro, Guamiranga e Mallet sob os aspectos da formação, último nivel da tabela de vencimento e variável do tempo que o professor leva para alcançar o último nível do plano de carreira, é necessário analisar alguns aspectos importantes desses municípios, como localização geográfica no Estado do Paraná, número de habitantes na área urbana e rural, e como se constituem, em linhas gerais, suas atividades econômicas.

De acordo com os dados do IPARDES (2020), o município de General Carneiro tem uma extensão territorial de $1.072,214 \mathrm{~km}^{2}$, distante da capital do Estado a $278,40 \mathrm{~km}$. O número estimado de habitantes no município é de 13.710. O município de Guamiranga possui extensão territorial de $243,549 \mathrm{~km}^{2}$, distante da capital do Estado é de 191,70 km, e conta com 8.739 habitantes. A extensão territorial do município de Mallet é de $752,023 \mathrm{~km}^{2}$, distante da capital do Estado é de 209,15 km, e contabiliza 13.630 habitantes em 2020. Sobre as atividades econômicas dos três municípios em tese, ligadas à agricultura, destacamos agropecuária, produção florestal, pesca e aquicultura, que são predominantes. Também são desenvolvidas atividades de silvicultura, criação de animais, extração vegetal e pesca em todos os municípios. Verificamos que as atividades econômicas nos municípios têm muita semelhança.

Com relação ao perfil das redes municipais de ensino, podemos pontuar, com base nos dados coletados no site do Ipardes (2020), que o município de General Carneiro conta com número total de 402 alunos matriculados na Educação Infantil; nas Creches, 99; na Pré-escola, 303; e no Ensino Fundamental Anos Iniciais, 797. Para esta oferta, a rede municipal de educação conta com 107 docentes divididos por modalidade de ensino: com 33 na Educação Infantil; 17 nas Creches, 17 na Pré-escola; e 40 no Ensino Fundamental Anos Iniciais.

Já o município de Guamiranga contabiliza um total de 284 matrículas na rede municipal na Educação Infantil; 42 nas Creches; 242 na Pré-escola; e 514 no Ensino Fundamental Anos Iniciais. Seu quadro docente tem 52 professores: 20 deles na Educação Infantil; 5 nas Creches; 17 na Pré-escola; e 34 no Ensino Fundamental Anos Iniciais.

O município de Mallet apresenta-se com 442 matrículas na Educação Infantil; 158 nas Creches; 254 na Pré-escola; e 722 no Ensino Fundamental Anos Iniciais. Conta com 103 professores, com 49 deles atuando na Educação Infantil; nas Creches, 26; na Pré-escola, 25; e no Ensino Fundamental Anos Iniciais, 64.

O principal indicador educacional no Brasil, atualmente, é o Índice de Desenvolvimento da Educação Básica (IDEB) , criado em 2007 pelo Instituto Nacional de Estudos e Pesquisas Educacionais Anísio Teixeira (INEP), formulado para medir a qualidade da aprendizagem em nível nacional. O IDEB é calculado a partir de dois componentes básicos: taxas de rendimento escolar (aprovação) e médias de desempenho em exames aplicados pelo INEP. Os órgãos oficiais utilizam o IDEB como parâmetro de qualidade do ensino básico do país.

O gráfico abaixo mostra dados do IDEB dos três municípios nos últimos anos de amostragem.

Gráfico 1. IDEB das escolas municipais nos anos de 2013 - 2015 e 2017

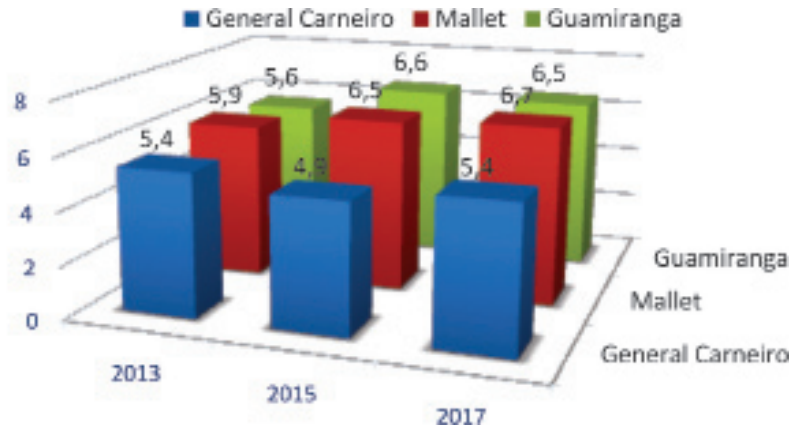

Fonte: Desenvolvido pela autora com dados do Ideb disponíveis no portal do MEC.

Oíndiceéutilizadoparamensurarofuncionamento das escolas públicas e privadas em nível nacional. Esse índice, em tese, observa o funcionamento do sistema educacional, fornecendo a média da população que teve acesso à escolarização, o fluxo de jovens e adultos que concluíram o Ensino Médio, bem como as crianças que cursam o Ensino Fundamental nos Anos Iniciais e Finais. Os dados revelam que o IDEB dos municípios de 
General Carneiro e Mallet vêm crescendo e estão acima da média nacional, que é de 5,6 nas escolas públicas municipais. O IDEB do município de Guamiranga, nos anos de 2013 e 2015, aumentou, mas ocorreu uma queda, em 2017, no percentual com relação aos últimos anos. O gráfico mostra pequenos avanços; contudo, no referente à realidade das escolas, esses são pouco significativos. Sobre isso, Paz e Raphae (2010, p. 14) ressaltam:

Verifica-se que os avanços na melhoria da qualidade da educação que resultam no IDEB, ocorrem em pequenos graus, [...]. Este pequeno avanço evidencia que, embora estejam sendo feitas inúmeras mudanças educacionais no financiamento, planos de desenvolvimento e investimentos em todas as etapas da educação, os passos rumo aos índices de primeiro mundo são bem morosos.

A qualidade da educação pública não está atrelada apenas à melhoria dos índices, pois eles revelam uma realidade inconsistente. As avaliações externas aplicadas para a obtenção dos índices resultam de políticas educacionais impostas. A valorização docente faz parte de políticas educacionais que visam à qualidade da educação. Freitas (2004) pondera que as avaliações externas focam na competitividade, e responsabilizam os docentes de forma injusta pelos baixos índices. Nesta seção, pontuamos que os municípios analisados são de pequeno porte, e todos têm sua economia pautada na agricultura. Com relação à rede municipal de educação, o município de General Carneiro tem um número maior de escolas com um IDEB menor em 2017, quando comparado com os outros municípios. Guamiranga tem o menor número de escolas entre os municípios analisados. Mallet tem o IDEB maior, acima da média nacional.

\section{A Carreira ocente nos Municípios De General Carneiro, Guamiranga e Mallet}

A partir da caracterização, tecemos algumas reflexões acerca do conceito de valorização. Para tanto, abordamos três aspectos importantes: a formação, vencimento e variável do tempo que os três municípios pesquisados oferecem aos seus professores, pois entendemos que esses são imbricados, ou seja, estão diretamente relacionados.

Com relação à formação, pontuamos que Masson e Morretti (2015), de posse dos dados do Instituto de Pesquisa Econômica Aplicada de 2012, revelam que os profissionais do magistério não recebem sua remuneração condizente com sua formação, visto que outros profissionais com a formação equivalente recebem valores maiores.

Em General Carneiro, a Lei de $\mathrm{N}^{\mathrm{o}}$ 621/00 instituiu o plano de carreira, e o último concurso público realizado no município foi o de $\mathrm{N}^{\mathrm{o}} 001 / 2014$, para professor do Ensino Fundamental Anos Iniciais, com carga horária de 20 horas. A exigência para o cargo era a formação em Magistério ou Licenciatura em Pedagogia, com remuneração de R\$776,28. Em Guamiranga, a Lei ${ }^{\circ}$ 202/2003 definiu o plano de cargos, carreira e salários e posteriormente foi alterada em seus artigos 34 e 36 pela Lei $\mathrm{N}^{\circ} 482 / 2009$, objetivando a estruturação do Quadro de Pessoal. O último concurso público realizado, conforme edital $n^{\circ} 01 / 2014$, ofereceu cargos para o regimento estatutário para professor I, podendo atuar na Educação Infantil e no Ensino Fundamental Anos Iniciais, sendo requisito apenas o Ensino Médio modalidade-Magistério ou Licenciatura em Pedagogia. A carga horária informada no edital era de 25 horas semanais, com remuneração inicial de R \$ 1.142,11.

Em Mallet, a Lei $N^{o} 1.236 / 15$ definiu o plano de carreira do município. Na sequência, o Projeto de Lei $\mathrm{N}^{\circ}$ 004/2016 foi aprovado, alterando o plano de carreira dos professores, aumentando a gratificação para diretores de CMEIS de $50 \%$ para $70 \%$, e excluindo o cargo de pedagogo, função que passou a ser executada pelos próprios professores do quadro do magistério. O último concurso público realizado em Mallet foi o de edital $n^{\circ} 01 / 2014$, que dispunha de cargo para professor do Ensino Fundamental com carga de 20 horas, exigência de Magistério ou Normal Superior e/ou Pedagogia, com remuneração inicial de $\mathrm{R} \$ 726,20$. O município de Mallet também realizou concurso para professores da Educação Básica Anos Iniciais de 40 horas, mas optamos por abordar o plano de carreira e os editais do concurso de 20 horas, por ser um dos critérios seletivos para a análise que compõe o trabalho.

Com relação à formação dos docentes das redes municipais, Grochoska (2016) destaca que o professor pode ser formado em duas perspectivas, sendo elas formação inicial e a formação continuada.

[...] a formação inicial é aquela que acontece por meio dos cursos médio modalidade normal ou superior nas licenciaturas habilitando professores para exercerem sua profissão, ela influência na carreira quando diz respeito ao ingresso e a habilitação; já a formação continuada é aquela que acontece durante a vida funcional deste professor, por meio de cursos de capacitação ou da pós graduação, nesse aspecto um dos pontos levantados diz respeito as licenças para estudo estabelecido ou não nas leis que regulamentam as carreiras (GROCHOSKA, 2016, p. 2).

Apresentamos a tabela abaixo para exemplificar o nível de escolarização previsto no último concurso público ofertado pelos três municípios, bem como para verificar o salário inicial no ano do concurso para ingressar na carreira docente.

Observamos que os municípios fizeram seu último concurso em 2014, e todos previam ingresso na carreira com nível médio magistério. A diferença salarial significativa entre Guamiranga e os municípios de 
Mallet e General Carneiro merece destaque. Entretanto, a faixa salaria oferecida nos municípios de General Carneiro e Mallet foi bastante próxima. Para Grochoska (2016), pensar a formação do professor no país, no viés de valorização, demanda não apenas oferecer cursos para serem concluídos pelos interessados. É necessário pensar estratégias de permanência desse docente na carreira, sendo de responsabilidade de todos os entes federados, União, Estados, Distrito Federal e Municípios. Os salários entre os profissionais que têm formação superior e os que não têm são os mesmos no início da carreira.

Tabela 1. Últimos concursos realizados nos municípios.

\begin{tabular}{l|l|l|l}
\hline Municipios & Ano de abertura & $\begin{array}{l}\text { Vencimento inicial previsto em } \\
\text { edital }\end{array}$ & Forma de ingresso \\
\hline General Carnciro & 2014 & RS $776,28 / 20$ horas & Magistério ou Pedagogia \\
Guamiranga & 2014 & RS 1.142,11/25 horas & Magistério ou Pedagogia \\
Mallet & 2014 & RS 726,20/20 horas & Magistério ou Pedagogia \\
\hline \hline
\end{tabular}

Fonte: Dados sistematizados pelas autoras.

Com relação ao vencimento, podemos pontuar que é o aspecto que define a permanência do docente na carreira. A Lei $\mathrm{N}^{\circ}$ 8.112, Art. 40 define vencimento caracterizando-o por "[...] retribuição pecuniária pelo exercício de cargo público, com valor fixado em lei” (BRASIL, 1990). Grochoska (2016) aponta para a questão de que o vencimento do profissional é um elemento que compõem a remuneração total do professor. Essa última é um elemento que se constitui por meio do vencimento, de vantagens, como gratificações, auxílios, dentre outros benefícios que estão elencados nos planos de carreira. Acarreira constitui um mecanismo legal com elementos e normas que o regulamentam e propiciam o desenvolvimento da vida funcional do professor, visando sua valorização ou não. Segundo Grochoska (2016), é a partir disso que o professor desenvolve suas atividades e chega até sua aposentadoria.

Os planos de carreira docente na Educação Básica no Brasil, e sua regulamentação vêm sendo tema de debates a partir da Constituição Federal de 1988. O art. 206, inciso $\mathrm{V}$, torna obrigatório contemplar os planos de carreira e o ingresso no magistério por meio de concurso público (BRASIL, 1988). A Emenda Constitucional $n^{o} 19 / 1998$ (BRASIL, 1998) garantiu o piso salarial nacional para o magistério por meio dos planos de carreira, que deveriam por meio de leis específicas a serem elaboradas e entrar em vigor em todos os estados, municípios e Distrito Federal (JACOMINI; PENNA, 2016). Os Estados e Municípios definem critérios próprios na elaboração dos planos de carreira, o que resulta em dificuldades de corrigir as disparidades no âmbito da carreira. Destacamos que a variável do tempo é um fator preponderante.

Com os dados levantados na pesquisa e analisando a variável tempo que os professores da rede municipal levam para alcançar o último nível de suas carreiras, percebemos que a existência dos planos de carreira nos três municípios não garante isonomia dentro da categoria. A variável do tempo deve ser considerada quando mencionamos a questão vencimento, pois são os elementos que denotam a valorização na carreira docente. Entretanto, o que verificamos é a existência de fatores que dificultam que os docentes alcancem o último nível do plano de carreira. Nos municípios em questão, o período mínimo é de vinte e um e vinte e sete anos, com uma média de vinte cinco anos.

O professor, no sistema capitalista, é um trabalhador assalariado, vende sua força de trabalho em troca do salário. Como todo o trabalhador em um sistema desigual e que visa o lucro acima de tudo, tem suas condições de trabalho precarizadas, que por vezes, impossibilitam suprir suas condições mínimas de existência. Segundo Marx e Engels (2007), um dos pontos cruciais que determinam os meios para satisfazer as necessidades do sujeito é a produção da sua vida material. Para Grochoska (2016), esses conceitos não compõem uma definição fechada, imutável e a-histórica; pelo contrário, são produtos históricos de um determinado período e podem ser alterados, conforme a sociedade, suas necessidades ou interesses. O conceito de valorização pode ser sistematizado de acordo com Grochoska (2016, p. 2):

[...] a valorização do professor é um princípio constitucional que se efetiva por meio de um mecanismo legal chamado carreira, que se desenvolve por meio de três elementos: a) Formação, b) Condições de trabalho e c) Remuneração, tendo como objetivos a qualidade da educação e a qualidade da vida do trabalhador.

Para subsidiar a valorização dos professores, no ano 2000 foi aprovada a Lei No 11.738, de 16 de julho, para instituir a Lei do Piso Salarial Profissional Nacional, que fixou um valor mínimo para que o profissional do magistério receba ao exercer suas funções (BRASIL, 2008). A respeito da valorização docente, Camargo et al. (2009, p. 342) afirmam que, no "[...] caso do magistério público, a remuneração é composta pelos vencimentos do cargo, acrescida de vantagens pecuniárias permanentes estabelecidas em lei [...]”. Em outras palavras, o salário base vai sendo acrescido com gratificações, vantagens por tempo de trabalho e até mesmo, em alguns casos, com vale transportes, entre outras. É importante ressaltar que as vantagens não são incorporadas no vencimento final dos docentes dos municípios pesquisados.

Citando Pinto (2009, p. 60), Grochoska (2016, p. 4) afirma que "não existe valorização de uma profissão sem salários atraentes, que estimulem os alunos do Ensino Médio a optar pela carreira". Assim, podemos 
observar o quanto a questão do vencimento do professor é importante para que a profissão seja valorizada e atrativa. Dentro dessa perspectiva de valorização docente, a Lei do Piso Salarial tem um viés de equidade, mas nem sempre é cumprida. Para Heck (2015), os entes federados não podem instituir o valor de remuneração abaixo do determinado pela Lei $\mathrm{N}^{\circ} 11.738 / 2008$ para docentes na carreira de magistério em nível médio, com carga horária não superior a 40 horas semanais. A autora salienta que a lei ajuda a regulamentar os planos de carreiras desses profissionais.

Sobre essa questão, somente General Carneiro incluiu a Educação Infantil nos planos de carreira. Porém, os profissionais que atuam nesses estabelecimentos não são contemplados com os vencimentos. A situação ocorre pelo fato de que, para atuar na Educação Infantil, existe um cargo denominado Atendente de Educação Infantil, e não professor. Em Guamiranga e Mallet não há distinção de vencimentos para o professor com formação mínima ou superior que atua na Educação Infantil e nos Anos Iniciais do Ensino Fundamental no início de carreira. O diferencial ocorre após o término do estágio probatório, quando cada professor irá se enquadrar nos seus respectivos níveis, de acordo com sua formação.

Os municípios de General Carneiro e Mallet, por exemplo, abriram concurso em 2014 ofertando vagas para o nível médio magistério ou Pedagogia, com carga horária de 20 horas semanais. No entanto, Guamiranga, que abriu concurso nesse mesmo período, estipulou 25 horas para professor I. Percebemos o aumento de carga horária de 5 horas para professor I, com uma remuneração inicial que difere dos municípios de Mallet no valor de R \$ 415,91, e de General Carneiro no valor de R\$365,83. Ao final da apresentação das tabelas de vencimentos e considerando a variável do tempo, pontuaremos se essa diferença permanecerá até o final de carreira dos docentes dos três municípios analisados.

\section{Tabelas Salariais e Planos de Carreira: Uma Breve Análise}

\section{Município de General Carneiro}

Apresentamos, na tabela 02, o plano de carreira de General Carneiro, que é subdivido em três classes, com onze níveis cada uma. A classe A é ocupada por profissionais que ingressam na carreira, possuindo a formação em nível médio magistério; a classe B referese àqueles profissionais com magistério acrescido de formação superior. Por fim, a classe $C$ é ocupada por profissionais com magistério, acrescido de graduação e pós-graduação, não há referência à formação em mestrado e doutorado.
Tabela 2. General Carneiro.

\begin{tabular}{|c|c|c|c|c|c|c|}
\hline Classes & $\begin{array}{c}\text { Classe } \\
\text { A }\end{array}$ & $\begin{array}{c}\text { Vencimento } \\
\text { classe A }\end{array}$ & Classe B & $\begin{array}{c}\text { Vencimento } \\
\text { classe B }\end{array}$ & Classe C & $\begin{array}{c}\text { Vencimento } \\
\text { classe C }\end{array}$ \\
\hline Niveis & 01 & $1.280,17$ & 12 & $1.920,26$ & 23 & $2.112,28$ \\
& 02 & $1.318,57$ & 13 & $1.977,87$ & 24 & $2.175,64$ \\
& 03 & $1.358,13$ & 14 & 2037,20 & 25 & 2240,90 \\
& 04 & $1.398,88$ & 15 & $2.098,32$ & 26 & $2.308,12$ \\
& 05 & $1.440,84$ & 16 & $2.161,27$ & 27 & $2.377,37$ \\
& 06 & $1.484,066$ & 17 & $2.226,10$ & 28 & $2.448,69$ \\
& 07 & $1.528,57$ & 18 & $2.292,88$ & 29 & $2.522,15$ \\
& 08 & $1.574,44$ & 19 & $2.361,66$ & 30 & $2.597,81$ \\
& 09 & $1.621,69$ & 20 & $2.432,71$ & 31 & $2.675,74$ \\
& 10 & $1.670,33$ & 21 & $2.505,69$ & 32 & $2.756,01$ \\
& 11 & $1.720,45$ & 22 & $2.580,88$ & 33 & $2.838,69$ \\
\hline
\end{tabular}

Fonte: Dados organizados pelas autoras com base no plano de carreira de General Carneiro.

As especificações contidas no plano, acerca da formação do profissional, refletem na classe que será ocupada, influenciando no seu vencimento. A Lei $\mathrm{N}^{\circ}$ $621 / 2000$, que institui o plano de carreira, traz, em seu art. $8^{\circ}$, as seguintes explanações: "a investidura em cargos que compõem a carreira do Magistério ocorrerá com a posse, sempre na classe e referência inicial cumprida a exigência de aprovação prévia em concurso público de provas e títulos [...]" (GENERAL CARNEIRO, 2000, p. 2). O professor, ao tomar posse do cargo, permanecerá na classe inicial, que corresponde formação a nível médio durante os três primeiros anos de estágio probatório, e mesmo que tenha formação em nível superior, estará em classe inferior à sua formação, com a respectiva remuneração, sendo a classe $\mathrm{A}$, nível 01 - inicial.

As progressões previstas no plano ocorrem a cada três anos, por merecimento ou titulação. A titulação possibilita ao profissional ascender de uma classe para a outra, por exemplo, de A para B, ou de B para C. O critério para progressão por merecimento ocorre pela realização de cursos, e prevê o avanço máximo de até dois níveis a cada elevação. O professor levará no mínimo 21 anos para alcançar o último nível da tabela. O plano tem um ponto interessante para análise, que diz respeito à necessidade de permanecer por um ano na classe B, para depois integrar a classe C. Tal situação aponta para a desvalorização da formação do professor dentro de seu plano de carreira, visto que sua formação não poderá ser contabilizada inicialmente, como é o caso da entrada com Ensino Superior, e a passagem de uma classe para a outra, quando o professor conclui um curso de pós-graduação.

\section{Município de Guamiranga}

O plano de carreira de Guamiranga (2003) apresenta os níveis identificados por letras, e os números que correspondem às classes a serem percorridas na tabela salarial, podendo ser representadas de 01 a 10 . 
A carreira dos profissionais que lecionam na Educação Infantil e nos do Ensino Fundamental Anos Iniciais $1^{\circ}$ ao $5^{\circ}$ ano é definida por vários critérios aprovados na Lei $\mathrm{N}^{\circ} 202 / 03$ que integram o plano aqui analisado. No entanto, o Plano sofreu alterações com a Lei $\mathrm{N}^{\circ}$ 482/2009 (GUARAMIRANGA, 2009)

Tabela 3. Guamiranga.

\begin{tabular}{ccccccccccc}
\hline Nivel & $\mathbf{1}$ & $\mathbf{2}$ & $\mathbf{3}$ & $\mathbf{4}$ & $\mathbf{5}$ & $\mathbf{6}$ & $\mathbf{7}$ & $\mathbf{8}$ & $\mathbf{9}$ & $\mathbf{1 0}$ \\
\hline Nivel & RS & RS & RS & RS & RS & RS & RS & RS & RS & RS \\
A & 1.517 & 1.593 & 1.669 & 1.744 & 1.820 & 1.896 & 1.972 & 2.048 & 2.124 & 2.200 \\
&, 36 &, 23 &, 09 &, 96 &, 83 &, 70 &, 57 &, 43 &, 30 &, 17 \\
Nivel & RS & RS & RS & RS & RS & RS & RS & RS & RS & RS \\
A1 & 1.650 & 1.733 & 1.815 & 1.898 & 1.981 & 2.063 & 2.146 & 2.228 & 2.311 & 2.393 \\
&, 84 &, 38 &, 92 &, 47 &, 01 &, 55 &, 09 &, 63 &, 18 &, 72 \\
Nivel & RS & RS & RS & RS & RS & RS & RS & RS & RS & RS \\
B & 1.661 & 1.744 & 1.827 & 1.910 & 1.993 & 2.077 & 2.160 & 2.243 & 2.326 & 2.409 \\
&, 60 &, 68 &, 76 & .84 &, 92 &, 00 &, 08 &, 16 &, 24 &, 32 \\
Nivel & RS & RS & RS & RS & RS & RS & RS & RS & RS & RS \\
C & 1.775 & 1.864 & 1.952 & 2.041 & 2.130 & 2.219 & 2.308 & 2.396 & 2.485 & 2.574 \\
& .41 & .18 & .95 & .72 & .49 & .26 &, 04 & .81 & .58 & .35 \\
\hline \hline
\end{tabular}

Fonte: Dados organizados pelas autoras com base no plano de carreira de Guamiranga.

Após a aprovação em concurso público, o vencimento docente corresponderá à classe 1 do valor inicial. O artigo 12 da lei, em seu parágrafo I, estabelece que "o professor de $1^{\circ}$ a $4^{\circ}$ série do Ensino Fundamental passarão por 3 níveis para efeito de promoção, com a qualificação ou habilitação mínima 01nível, para efeito de enquadramento (GUAMIRANGA, 2003, p. 4)". O nível A contempla os professores formados em nível médio magistério, e A1 é utilizado para formação magistério mais estudos adicionais. $\mathrm{O}$ nível $\mathrm{B}$ corresponde aos docentes com formação magistério mais licenciatura plena em área da Educação. No que se refere ao nível $\mathrm{C}$, considera o magistério, licenciatura mais pós-graduação na área da Educação, mas não contempla os níveis de mestrado e doutorado. $\mathrm{O}$ avanço na carreira poderá ser na horizontal, sendo a progressão funcional; ou na vertical, seguindo promoção de uma classe para outra. Vale salientar que para, o professor alcançar o último nível do plano de carreira, levará no mínimo 27 anos.

\section{Município de Mallet}

O plano de carreira do magistério, no município de Mallet, foi instituído pela Lei $\mathrm{N}^{\circ} 1.236 / 2015$ (MALLET, 2015) e é utilizado para a efetivação via concurso público. De acordo com o Plano, o docente passa pelo estágio probatório sendo avaliado pelos seguintes critérios: Assiduidade, disciplina, capacidade de iniciativa, produtividade, responsabilidade e eficiência. Em relação à titulação dos professores que atuam, a maioria tem formação em Pedagogia e magistério, mas ainda há professores formados em outras licenciaturas, as quais, segundo a Secretária da Educação do Município, estão cursando Licenciatura em Pedagogia.

Na comprovação de títulos, o doutorado tem peso de 2 pontos; mestrado 1,5; e curso de especialização (lato sensu) com carga horária mínima de 360 horas tem de pontuação de 2,5. É importante perceber a falta de valorização da titulação docente, pois o docente com a especialização lato sensu é privilegiado, e aquele com pós-graduação stricto sensu (mestrado e doutorado) é desvalorizado. Em relação aos níveis do cargo de professor que seguem a ordem vertical, serão associados à habilitação ou titulação, sendo válidos o magistério, licenciatura plena, especialização (lato sensu), pósgraduação (stricto sensu).

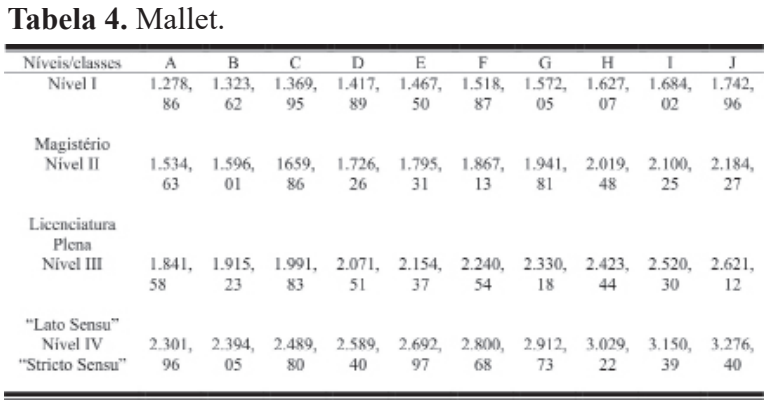

Fonte: Dados organizados pelas autoras com base no plano de carreira de Mallet.

As classes que compõe a ordem horizontal vão de A a J, e é realizada uma avaliação de desempenho feita pela Secretaria Municipal. No plano de carreira consta que o professor só poderá atuar na organização pedagógica e classe especial se for formado em licenciatura plena em Pedagogia e com pós-graduação com carga horária maior que 360 horas. O Plano de Carreira, em seu capítulo VII, destaca a remuneração, vencimento e gratificações, constituído pelos níveis I, II, III e IV, compostos pelas classes de A a J, as quais tinham o acréscimo de 3,5\% sucessivamente até atingir a última classe. No nível IV, o percentual era de 4\%. O professor da rede municipal de Mallet leva 27 anos, no mínimo, para alcançar o último nível do plano de carreira.

\section{Planos de Carreira dos Municípios: Algumas Considerações}

Apontamos nos planos de carreira dos três municípios que a movimentação do professor, para percorrer os níveis estipulados nas tabelas salariais, dependerá do desempenho profissional e interesse em participar de cursos de capacitação. As prefeituras oportunizam alguns cursos de formação continuada para capacitação, que são descritos em cada plano. Portanto, a análise da variável do tempo que cada professor levará 
do início até ao fim da tabela salarial poderá ter muitos empecilhos para avançar ao próximo nível ou classe, seja na horizontal ou vertical. Um exemplo consiste no plano de carreira de Guamiranga, que estabelece que, para a progressão desses profissionais, se faz necessária uma avaliação anual de desempenho e capacitação profissional.

Caso os profissionais correspondam a essas exigências, poderão alcançar a progressão funcional em um período de três anos, contados da data de enquadramento em determinada referência (GUAMIRANGA, 2003), como descrito no artigo $2^{\circ}$ do Plano:

[...] perde o direito [à] avaliação de desempenho o servidor que durante o período de 03 (três) ano do interstício: a) receber formalmente 3 (três) advertências ou I (uma) suspensão do serviço; b) falta ao serviço, sem motivo justificado em dias consecutivos ou alternados, em número igual ou superior a 10 (dez) dias úteis; c) estiver enquadrado, incurso ou for julgado culpado em processo administrativo (GUAMIRANGA, 2003, p. 7).

A avaliação de desempenho nos municípios analisados, é realizada pela chefia do departamento de Educação, essa empossada pelo prefeito atuante. Abordando a problemática da valorização docente, Scheibe (2010), apresenta a questão da existência do curso de nível médio para formação de professores, enfatizando dois movimentos diferentes, tendo, por um lado, defesas à continuidade dessa formação, enquanto inversamente outros grupos apontam para sua extinção. Para o grupo que defende a permanência da formação em nível médio, uma das razões para sua manutenção seria "[...] a alegação da impossibilidade de, a curto prazo, dar conta de formar todos os docentes em nível superior, particularmente aqueles que se destinam à Educação Infantil e aos Anos Iniciais do Ensino Fundamental" (SCHEIBE, 2010, p. 993).

A possibilidade de formação em nível médio de professores está alicerçada na Lei de Diretrizes e Bases da Educação Nacional (BRASIL, 1996). Scheibe (2010) defende a ideia de que seria necessário chegar a um nível de formação de professores com maior aprimoramento, e isso se consolidaria pela formação em nível superior. Ao mesmo tempo, Masson e Vaz (2016), trabalham a questão da desvalorização docente, especialmente sobre a oferta e a demanda de pedagogos no Estado do Paraná. É de extrema importância ressaltarmos que o pedagogo é o profissional habilitado para a atuação na Educação Infantil, nos Anos Iniciais do Ensino Fundamental e na Gestão Educacional.

Ao desenvolverem suas análises, as autoras apontam, por meio de dados fornecidos pelo site da Secretaria Estadual de Educação do Paraná e informações fornecidas por 37 das 122 instituições de Ensino Superior do mesmo Estado que há excedente de profissionais formados em relação às novas funções. Ao analisarmos a questão desse excedente de pessoas com formação em nível superior, faz-se necessário contextualizar a realidade vivida, pois estamos inseridos nas leis de mercado. Masson e Vaz (2016) destacam que a atividade do professor é importante para o desenvolvimento social, e na sociedade capitalista, ganha conotação de trabalho assalariado.

O professor é um profissional assalariado, e influenciado pelas leis do mercado de trabalho, sofre as consequências do excedente de oferta em relação à procura, e por esses motivos ocorrem os baixos vencimentos. As autoras apontam que o problema não afeta somente as pessoas que estão fora do mercado de trabalho, pois os profissionais que estão exercendo sua profissão observam a grande oferta de pessoal e o risco de demissão, e acabam por se submeterem a condições precárias de trabalho. $\mathrm{O}$ que explica o requisito mínimo de formação em nível médio dos professores é a questão econômica dos municípios, que optam por receberem profissionais que custarão menos aos cofres públicos, com formação mínima para o exercício da docência.

Ao retomarmos o objetivo do estudo, que é o de compreender se há ou não a valorização da carreira dos docentes nos municípios de General Carneiro, Guamiranga e Mallet - PR, abordando os aspectos de formação, último nível da tabela de vencimento e a variável do tempo que o professor leva para alcançar o último nível do plano de carreira, pontuamos que não ocorre a valorização dos docentes. Não existe valorização mesmo com planos de carreira que, em tese, deveriam garantir e efetivar essa em sua concretude.

\section{Considerações Finais}

Ao final do estudo observamos, pelos três aspectos abordados, formação, vencimento e variável do tempo, que os municípios de General Carneiro, Guamiranga e Mallet não valorizam a carreira docente. Sobre o aspecto da formação, podemos destacar que é a formação inicial em nível médio que prevalece no ingresso desse profissional na carreira docente nos três municípios e, dessa forma, os gestores municipais, com aval das Secretarias de Educação do Município, remuneram seus profissionais da Educação com salários que estão abaixo do seu nível de formação. Não há incentivos, por parte do poder público, para que os docentes invistam em uma formação em nível de mestrado e doutorado. Mesmo que o façam, alguns planos de carreira não contemplam essa formação no que tange ao vencimento final da tabela salarial. Sobre o aspecto do vencimento, ocorrem impeditivos que dificultam os docentes das redes a perfazer todas as classes e níveis das tabelas salariais, afetando diretamente o vencimento final 
da carreira docente, devido aos critérios de avaliação adotados pelas secretarias municipais de Educação. A média de tempo que os docentes levam para alcançar o último nível do plano de carreira é de, no mínimo, 25 anos, caso consigam alcançar.

$\mathrm{O}$ presente estudo indica a necessidade da produção de pesquisas que abordem o escopo, no sentido de que a desvalorização docente vem ocorrendo de maneira constante e o poder público utiliza de mecanismos legais para efetivá-la, o que compromete a Educação pública municipal.

\section{Nota}

1. Informações disponíveis no site do Ministério da Educação.

\section{Referências}

BRASIL. Constituição da República Federativa do Brasil de 1988. Brasília, 1988. Disponível em: Disponível em: http://www.planalto.gov.br/ccivil_03/ constituição

/constituicaocompilado. Acesso em: 7 jan. 2020.

Constituição (1988). Emenda constitucional $n^{\circ} 19$, de 04 de junho de 1988. Modifica o regime e dispõe sobre princípios e normas da administração pública [...]. Disponível em: http://www.planalto.gov.br/ ccivil 03/Constituicao/Emendas/Emc/emc19.htm. Acesso em: 01 jan 2020.

Lei $\mathrm{n}^{\circ} 11.738$, de 16 de julho de 2008. Institui o piso salarial profissional nacional para os profissionais do magistério público da educação básica. Disponível em: http://www.planalto.gov.br/ccivil_03/_ato20072010/2008/lei/l11738.htm

Acesso em: 09 ago. 2019.

. Lei $\mathrm{n}^{\circ} 8.112$ de 11 de dezembro de 1990. Dispõe sobre o regime jurídico dos servidores públicos civis da União, das autarquias e das fundações públicas federais. Disponível em: http://www.planalto.gov.br/ ccivil_03/leis/18112cons.htm. Acesso em: 08 jul 2019.

. Lei $\mathrm{n}^{\circ}$ 9.394, de 20 de dezembro de 1996. Estabelece as Diretrizes e Bases da Educação Nacional. Disponível em: http://www.planalto.gov.br/ ccivil_03/leis/19394.htm. Acesso em: 08 jul. 2019.

Ministério da Educação. IDEB: Apresentação. Disponível em: portal.mec.gov.br > conheca-o-ideb. Acesso em: 05 out. 2019.

CAMARGO, R. B., et al. Financiamento da Educação e remuneração docente: um começo de conversa em tempos de piso salarial. Revista Brasileira de Política e Administração de Educação. Porto Alegre, v. 25, n. 2, p. 185-384, mai./ago. 2009

FREITAS, L. C. A Avaliação e as reformas dos anos de 1990, novas formas de exclusão, velhas formas de subordinação. Educação e Sociedade, Campinas, v. 25 , n. 86,2004 . Disponível em: http://www.scielo.br/scielo.php?pid=S0 $10173302004000100008 \&$ script $=$ sci_abstract\&tlng=pt. Acesso em: 06 out. 2019.

GENERAL CARNEIRO. Lei n ${ }^{\circ}$ 621/2000. Plano de Empregos, Carreira e remuneração do Magistério Público Municipal de General Carneiro (PR). Câmara Municipal de General Carneiro: General Carneiro, 2000. $\overline{001 / 2014}$

Prefeitura Municipal. Edital $n^{\circ}$ 001/2014. Concurso Público $n^{\circ}$

GROCHOSKA, M. A. Valorização do professor: a trajetória das legislações que regulamentam a carreira dos professores de educação básica no município de São José dos Pinhais. In: Anped Sul, 11., 2016. Curitiba. Anais. Curitiba. 2016. 01-12.

GUAMIRANGA. Prefeitura Municipal. Concurso Público n 001/2014. Edital n ${ }^{\circ} 001 / 2014$.

GUAMIRANGA. Câmara Municipal. Lei n 202/2003. Plano de Empregos,
Carreira e remuneração do Magistério Público Municipal de Guamiranga (PR). Câmara Municipal de Guamiranga, 2003.

Lei $n^{\circ}$ 482/2009. Altera dispositivos da Lei no 202 de 15/12/2003 Plano de Cargos, Carreira e Salários dos Profissionais da Educação da Rede Municipal de Ensino, e dá outras providências, 2003.

HECK, B. T. M. Os dilemas da carreira docente na educação infantil. CONGRESSO BRASILEIRO DE EDUCAÇÃO, 12, 2015. Anais. Curitiba: PUCPR, 2015, p. 39746-39763.

INSTITUTO PARANAENSE DE DESENVOLVIMENTO ECONÔMICO E SOCIAL - IPARDES. Instituição de pesquisa vinculada à Secretaria de Estado do Planejamento e Projetos Estruturantes - SEPL. Paraná, 2020

Disponível em: http://www.ipardes.pr.gov.br/Pagina/Cadernos-municipais Acesso em: 08 jul. 2019.

JACOMINI, M. A.; PENNA, M. G. O. Carreira docente e valorização do magistério: condições de trabalho e desenvolvimento profissional. Campinas. Pro.Posições - V. 27, N. 2 (80) | maio/ago. 2016. Disponível em: https://periodicos.sbu.unicamp.br/ojs/index.php/proposic/article/ view/8647238/14191

Acesso em: 8 jun. 2019.

MALLET. Prefeitura Municipal. Lei $n^{\circ} 1236 / 2015$. Plano de Empregos, Carreira e remuneração do Magistério Público Municipal de Mallet (PR). Câmara Municipal de Mallet: Mallet, 2015.

Concurso Público n 001/2014. Edital nº01/2014

Projeto de lei $n^{\circ} 04$. Altera a redação do artigo 29, inciso III, o anexo

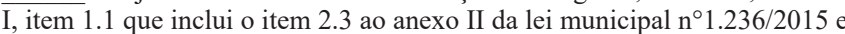
dá outras providências. Câmara municipal de Mallet. Mallet, 2016.

MARX, k.; ENGELS, F. A ideologia alemã. Tradução Luis Carlos de Castro e Costa $-3^{\circ}$ ed. São Paulo: Martins Fontes, 2007.

MASSON, G.; MORETTI, J. S. S. A valorização dos professores em municípios do Paraná: análise dos planos de carreira. Jornal de Políticas Educacionais. v.9, n.17 e 18, 111-124, jan./jun. e ago/dez. 2015

MASSON, G.; VAZ, M. R. T. A oferta e a demanda de pedagogos no Paraná (2009-2013): implicações na (des) valorização profissional. In: Anped Sul, 11., 2016. Curitiba. Anais. Curitiba. 2016. 01-11.

PAZ, F. M.; RAPHAE, H. S. (2010). O IDEB e a qualidade da educação no ensino fundamental: fundamentos, problemas e primeiras análises comparativas. Omnia Humanas, Adamantina, SP, 3 (1), 7-30. Disponível em: http://www.fai.com.br/portal/ojs/index.php/omniahumanas/article/view/81. Acesso em: 08 jul 2019.

SCHEIBE, Leda. Valorização e formação dos professores para a educação básica: questões desafiadoras para um novo plano nacional de educação. Educação e Sociedade. Campinas, v.31, n. 122, p. 981-1000, jul./set. 2010 